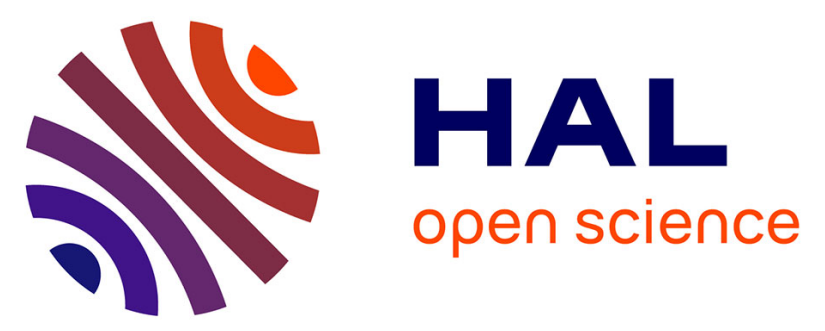

\title{
PULSED LASER AND ELECTRON BEAM INDUCED DIFFUSION OF ANTIMONY IN SILICON
}

\author{
E. Fogarassy, P. Siffert, Damien Barbier, G. Chemisky, A. Laugier
}

\section{To cite this version:}

E. Fogarassy, P. Siffert, Damien Barbier, G. Chemisky, A. Laugier. PULSED LASER AND ELECTRON BEAM INDUCED DIFFUSION OF ANTIMONY IN SILICON. Congress On Laser-Solid Interactions And Transient Thermal Processing Of Materials, 1983, Strasbourg, France. pp.C5-241C5-245, 10.1051/jphyscol:1983538 . jpa-00223124

\section{HAL Id: jpa-00223124 https://hal.science/jpa-00223124}

Submitted on 1 Jan 1983

HAL is a multi-disciplinary open access archive for the deposit and dissemination of scientific research documents, whether they are published or not. The documents may come from teaching and research institutions in France or abroad, or from public or private research centers.
L'archive ouverte pluridisciplinaire HAL, est destinée au dépôt et à la diffusion de documents scientifiques de niveau recherche, publiés ou non, émanant des établissements d'enseignement et de recherche français ou étrangers, des laboratoires publics ou privés. 


\title{
PULSED LASER AND ELECTRON BEAM INDUCED DIFFUSION OF ANTIMONY IN SILICON
}

\author{
E. Fogarassy, P. Siffert, D. Barbier ${ }^{*}$, G. Chemisky ${ }^{\star}$ and A. Laugier ${ }^{\star}$ \\ Centre de Recherches Nucléaires, Laboratoire PHASE, 67037 Strasbourg Cedex, \\ Fronce \\ *INSA, 69621 ViZZeurbonne Cedex, Fronce
}

\begin{abstract}
Résumé - Le but de ce travail est de comparer la diffusion induite, soit par une impulsion laser, soit gar un faisceau d'électrons pulsés, d'un film mince d'antimoine d'environ $100 \AA$ d'épaisseur dans un substrat cristallin de silicium. Les résultats déduits d'expériences de rétrodiffusion de particules chargées (RBS), sont interprētês en utilisant les profil de distribution des températures dans les zones traitées, obtenus en résolvant 7 'êquation de la chaleur pour chacune des deux techniques de recuit (laser et électrons).

Abstract - The aim of this work is to compare the diffusion into silicon of a thin $\mathrm{f} i \mathrm{~m}$ ( $\sim 100 \AA$ ) of deposited antimony induced either by a pulsed laser irradiation or electron beam and to interpret the different experimental behaviours as observed by Rutherford backscattering spectrometry, by using the calculated temperature distributions obtained by solving the heat flow equation for the two different annealing processes.
\end{abstract}

\section{INTRODUCTION}

It has been demonstrated in previous works, that pulsed laser /1, 2/ or electron beams $/ 3 /$ can be used to introduce into the silicon lattice dopants deposited on the surface that diffuse rapidly in the melted Tayer. The purpose of this study is to compare, by Rutherford backscattering spectrometry (RBS), the distribution of antimony in silicon, its incorporation in substitutional sites, and the disorder produced near the surface by using these two different types of localized heating source. The experimental results have been interpreted on the basis of the thermal models obtained, by solving the heat flow equations, respectively for the pulsed laser and electron beam processing.

\section{EXPERIMENT}

Thin films of high purity antimony have been deposited by vacuum evaporation ( $p \simeq 10^{-6}$ torr), on monocristalline silicon substrates of $\langle 111\rangle$ orientation. The thickness of the deposited layers in the range of 100 to $120 \AA$, has been measured by using the quartz monitor. The amount of dopant deposited, as deduced from RBS experiments ranged from $3.3 \times 10^{16}$ and $3.7 \times 10^{16} \mathrm{~cm}^{-2}$.

The results given by the experimental procedures have been found to be in good agreement.

The samples covered with the dopant film have been irradiated with a pulsed laser or electron beams under the following conditions :

- The laser treatment has been performed either in air or under vacuum ( $\mathrm{q} \sim 10^{-5}$ torr) using the amplified monomode out put of a 20 ns duration pulsed ruby laser, emitting energy densities in the range 1 to $2 \mathrm{~J} / \mathrm{cm}^{2}$;

- Electron beam pulses of $50 \mathrm{~ns}$ in duration were used with two different electron spectral energy distributions refered as type a (mean electron energy $\bar{E}=12 \mathrm{KeV}$ ) 
and type $b(\bar{E}=16 \mathrm{KeV})$. The energy densities were in the $0.8-1.5 \mathrm{~J} / \mathrm{cm}^{2}$ range. In all cases, the evaporation losses of antimony during irradiation as measured by RBS, have been found less than 15\% of the initial amount of deposited dopant.

The distribution profiles of both total and substitutional dopant were determined by RBS measurements performed under random and channeling conditions with a ${ }^{4} \mathrm{He}^{+}$ion beam of $1-2 \mathrm{MeV}$ energy. The backscattered particles were detected by means of a surface barrier detector. This arrangement gives an equivalent depth resolution of about $200 \AA$ for $S i$.

\section{RESULTS}

Figure 1 reports the results obtained for a $120 \AA$ Sb film on Si after laser irradiation, in air, at $E=1.45 \mathrm{~J} / \mathrm{cm}^{2}$. The dopant profile mainly consists of an in-depth distribution, with a highly substitutional sb concentration of $1.2 \times 10^{21}$ $\mathrm{cm}^{-3}$, close to the solubility limit achieved by laser annealing $\left.\left(c_{5} \times 1.3 \times 10^{21} \mathrm{~cm}^{-3}\right) / 4\right)$ and largely in excess of the thermal equilibrium solubility $\left(C_{s}^{0} \sim 6 \times 10^{19} \mathrm{~cm}^{-3}\right.$ at $T=1200^{\circ} \mathrm{C}$ ).

The fraction of the initially deposited Sb atoms, which has diffused in depth into the substrate, is in the order of $80 \%$. About $50 \%$ of this fraction is incorporated in substitutional sites into the silicon lattice. A similar behaviour is observed for laser treatments performed under vacuum.

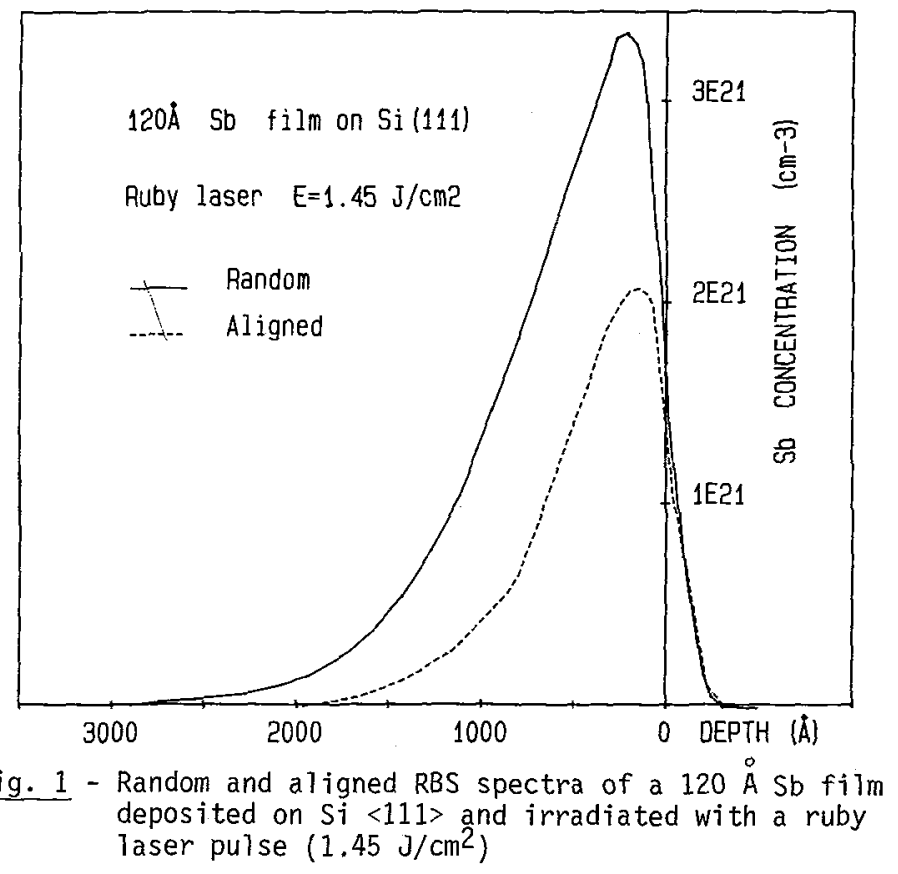

Figure 2-1 shows the Sb distribution profiles under random and channeling conditions after type b pulsed electron irradiation at $E=1.3 \mathrm{~J} / \mathrm{cm}^{2}$, of a $100 \AA \mathrm{Sb}$ deposited layer. In this case, a highly disordered surface layer is observed. Behind this surface peak, substitutional sb extends in depth into silicon substrate. The substitutional fraction represents only $6 \%$ of the amount of deposited $\mathrm{Sb}$ atoms. The maxi- 


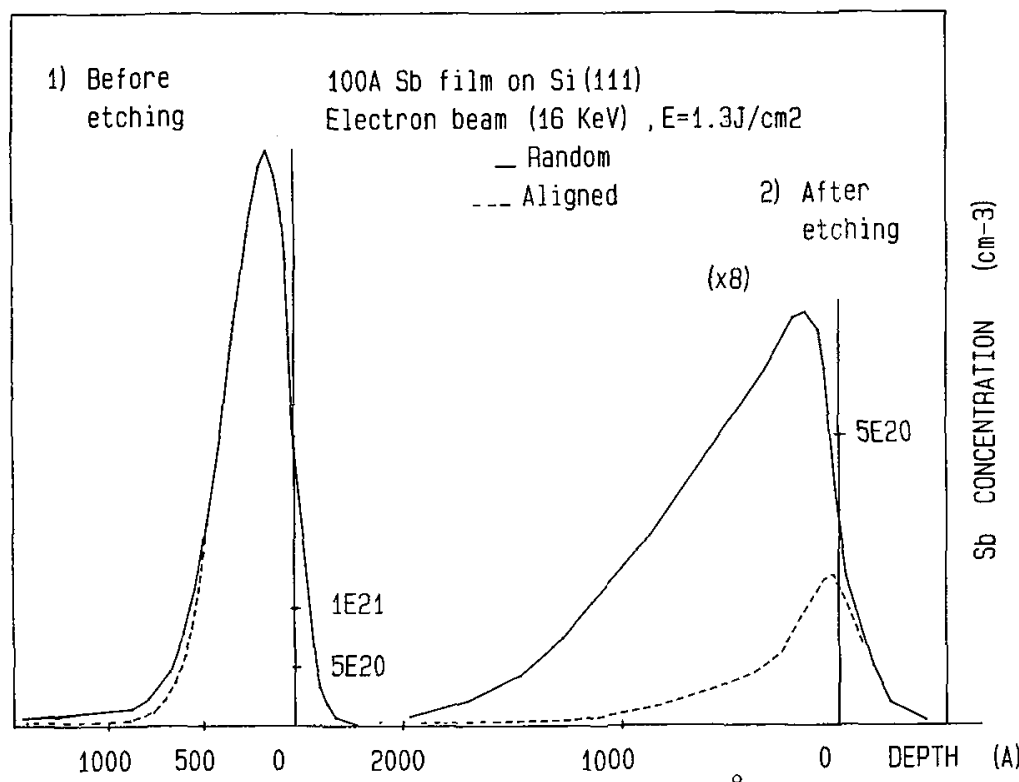

Fig. 2 - Random and aligned RBS spectra of a $100 \AA \mathrm{Sb}$ film deposited on $\mathrm{Si}\langle 111\rangle$ and irradiated with an electron beam pulse $\left(1.3 \mathrm{~J} / \mathrm{cm}^{2}\right)$
1) before teching
2) after etching

mum substitutional concentration $\left(\sim 6.5 \times 10^{20} \mathrm{~cm}^{-3}\right.$ ) has been deduced from channeling exp-riments (Fig. 2.2) performed after etching of the disordered Sb surface Tayer which contains about 75\% of the initial deposited Sb atoms. A similar behaviour is obtained with type a electron beam pulsed at $1.0 \mathrm{~J} / \mathrm{cm}^{2}$.

\section{INTERPRETATION OF THESE RESULTS}

Considering a strictly thermal approach, we can assume that the energy is fully transfered to the silicon lattice leading to superficial melting. During this melting process, diffusion in liquid phase $\left(D_{\mathrm{L}} \sim 10^{-4} \mathrm{~cm}^{2} / \mathrm{sec}.\right)(5)$ occurs from the surface as we 11 established now in the literature. During the epitaxial regrowth the melt front velocities, as deduced from heat flow calculations $(6,7)$, are respectively $3 \mathrm{~m} / \mathrm{s}$ for the laser process and $2 \mathrm{~m} / \mathrm{s}$ for the electron beam process (type $a$ and $b$ ).

For these values, the interfacial segregation coefficient $K=C S / C L$ are much higher than the thermal equilibrium segregation coefficient ( $K_{0}=0.023$ for antimony). As shown in a previous work (8), the linear relation :

$$
C_{S}=C_{S}^{0} \times \frac{K}{K_{0}} \text { allows to deduce the value of } k \text { From the measured value of }
$$

$C_{s}$ (al] symbols have the same meaning as in Ref. 8). The results are $k \sim 0.25$ for the electron beam and $k \sim 0.5$ for the laser, respectively.

In this case, the lower substitutional Sb concentration, associated with the surface disordered layer after electron beam processing may be correlated to the lower value of the interfacial segregation coefficient, by this later irradiation technique.

\section{DISCUSSION}

The prevent results can be discussed on the basis of a detailed analysis of the pulsed electron beam induced thermal process in silicon. 
On Figure 3, we have compared the enthalpy distribution in the irradiated layer for the two different heating processes. First, one can see, in the case of the laser beam, that the latent heat is exceeded all over the melting layer. By contrast, on the same Figure, it appears that this behaviour is different for the electron beam, because of a more penetrating energy deposition profile, which depends on the electron energy distribution. The less penetrating electron beam pulse (type a) induces the deepest fully molten zone. According to this particular feature, the incorporation of substitutional $\mathrm{Sb}$ is less probable in the melting zone by comparison with a fully molten zone as observed on Fig. 2, corresponding to type b electron beam processing.

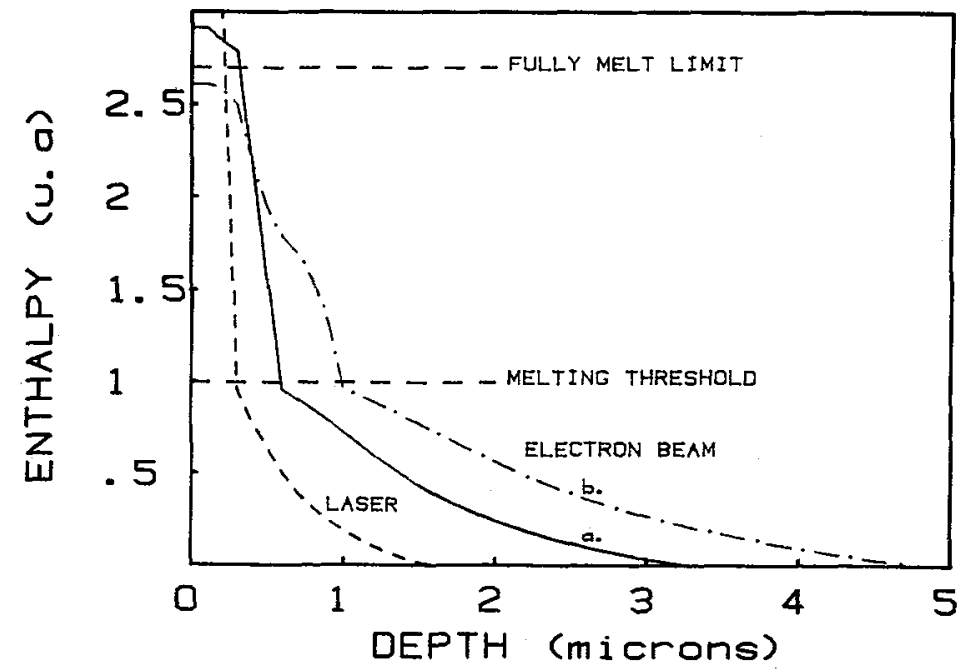

Fig. 3 - Calculated enthalpy distribution profiles in laser and electron beam treated samples.

In order to confirm this model we have used the two types of electron beams previously described. The corresponding distribution profiles, as deduced from RBS experiments (Fig. 4 for type a and 5 for type b) show a considerably larger extent of $\mathrm{Sb}$ atoms in the case of the less penetrating electron (type a) heating procedure.

\section{CONCLUSION}

Our investigations have demonstrated that the behaviour of antimony in silicon is quite different after pulsed laser and electron beam processing. We have shown that an interpretation, based only on a segregation effect of the impurity, at the liquid-solid interface, during the regrowth of the molten zone, is not entirely satisfactory. The more detailed analysis we undertook considers also the differences of the enthalpy distributions in the treated layers. The enthalpy distribution gradient, obtained with the pulsed electron beam, much lower than in the case of pulsed laser, leads to induce a zone melting mechanism, where the diffusion of impurity and its incorporation into the silicon lattice is less probable than in a fulty molten layer, resulting from the pulsed laser treatment. This interpretation is in good agreement with the experimental results. 


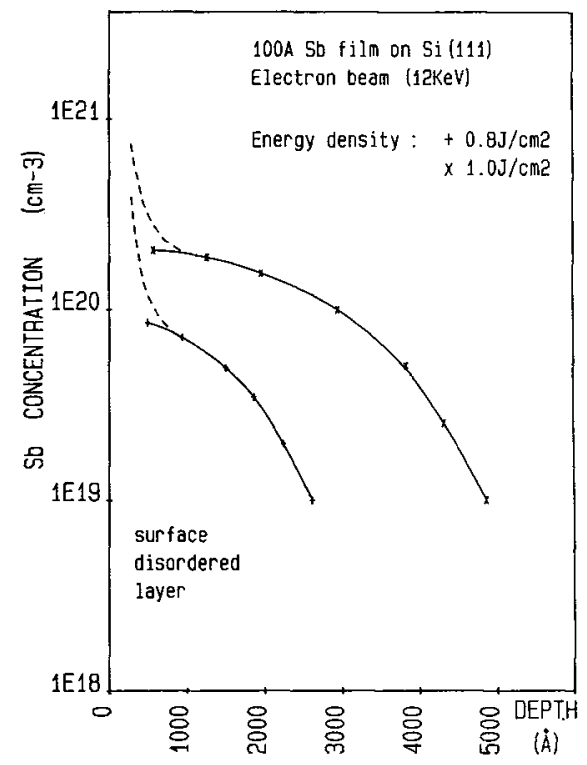

.ig. 4 - Random RBS spectra of a $100 \AA$ Sb film deposited on $\mathrm{Si}\langle 111\rangle$ and irradiated with an electron beam pulse

(type a, 0.8 and $1.0 \mathrm{~J} / \mathrm{cm}^{2}$ )

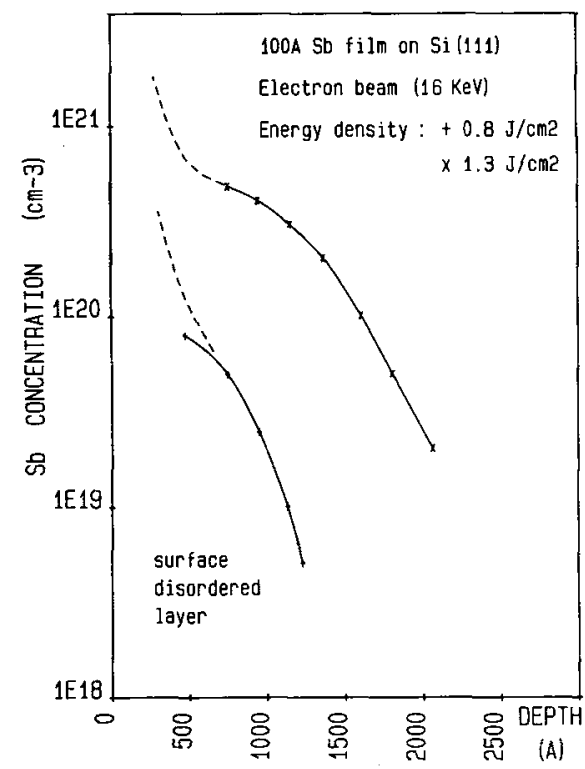

Fig. 5 - Random RBS spectra of a $100 \AA \mathrm{Sb}$ film deposited on $\mathrm{Si}<111>$ and irradiated with an electron beam pulse (type b, 0.8 and $1.3 \mathrm{~J} / \mathrm{cm}^{2}$ )

\section{REFERENCES}

1. J. NARAYAN, R.T. YOUNG, R.F. WOOD and W.H. CHRISTIE. Appl. Phys. Letters 33 (4) (1978) 338.

2. E. FOGARASSY, R. STUCK, J.J. GROB and P. SIFFERT. J. Appl. Phys. 52 (2) (1981) 1976.

3. M. MAENPÄÄ and H.A. NICOLET. "Laser and electron beam processing of materials" (Edited by C.H. WHITE and P.S. PEERCY, Academic Press (1980) 556.

4. C.W. WHITE. J. Appl. Phys. 51 (1) (1980) 738.

5. H. KODERA. Japan J. Appl. Phys. 2 (1963) 212.

6. M. TOULEMONDE, R. HEDDACHE (unpubi ished).

7. G. CHEMISKI, D. BARBIER and A. LAUGIER. "European MRS Conference" 27-27 May 1983, Strasbourg.

8. R. STUCK, E. FOGARASSY, J.J. GROB and P. SIFFERT. Appl. Phys. 23 (1980) 15. 